\title{
TREATMENT OF FEMORAL NECK FRACTURES WITH A CANCELLOUS SCREW AND FIBULAR GRAFT
}

\author{
O. N. NAGI, V. K. GAUTAM, S. K. S. MARYA
}

From the Postgraduate Institute of Medical Education and Research. Chandigarh

\begin{abstract}
Twenty-six patients with femoral neck fractures were treated by open reduction, cancellous screw fixation and free fibular grafting. The patients were between 14 and 50 years of age. There were 16 old and 10 fresh fractures. Four patients had radiological signs of avascular necrosis before the treatment was instituted. Bony union was achieved in all patients except one, where the failure occurred because of a technical error. The patients were followed up for at least two years. No new case of avascular necrosis was detected after treatment, and there was clinical and radiological improvement in all four patients with pre-operative avascular necrosis.
\end{abstract}

Despite a plethora of technical and biomechanical advances in orthopaedics in the last two decades, the problem of the "unsolved fracture" is still with us. Replacement surgery, either partial or total, remains the treatment of choice for the fractured neck of femur in the elderly patient (D'Arcy and Devas 1976; Devas 1977; Coats and Armour 1979: Cartlidge 1981). The struggle to find the best treatment in the relatively younger patient continues as relentlessly as it did half a century ago. The prognosis is all the more gloomy if, as often happens in India, the patient presents several months after the injury, often with resorption of the neck and sometimes with radiological signs of avascular necrosis.

In the middle of 1981 we started treating these patients by open reduction, cancellous screw fixation and fibular grafting. All the fractures united, even those with gross resorption of the neck and signs of avascular necrosis. The procedure was then tried in all subsequent cases of femoral neck fractures of Garden Types III and IV which presented early; the results were equally gratifying. This revived our interest in a procedure that had been tried in the past with less encouraging results (Inclan 1946: Patrick 1949).

\section{MATERIAL AND METHODS}

Twenty-six patients were operated on between May 1981 and January 1983 in the Department of Orthopaedics at the Postgraduate Institute of Medical Education and

O. N. Nagi, MSOrth. MSc, MAMS. Associate Professor V. K. Gitutam. MSOrth. Senior Resident

Department of Orthopaedies. Postgraduate Institute of Medical Education and Research. Chandigarh 160012. India.

S. K. S. Marya. MSOrth. Senior Resident

Department of Orthopaedics. All India Institute of Medical Sciences. New Delhi 110028 . India.

Requests for reprints should be sent to Dr O. N. Nagi.

(- 1986 British Editorial Society of Bone and Joint Surgery

$0301620 \times 863062 \$ 2.00$
Research, Chandigarh. The patients who could be operated upon within three weeks of injury were labelled as "fresh" cases; the others as "old". There were 16 old and 10 fresh cases.

Case selection. Initially, patients below 50 years of age with an old fracture of the femoral neck, where ordinarily McMurray's osteotomy would have been performed, were selected for this new procedure. Partial resorption of the neck with avascular necrosis was not considered a contra-indication. The length of the neck was noted on anteroposterior films taken with the limb in medial rotation. Good results encouraged us to continue with further patients, and then to use this procedure routinely in all patients below 50 years of age with displaced fractures of the femoral neck.

Technique. The procedure is carried out on a standard operating table. To expose the hip we used Moore's posterior approach in the first three cases and WatsonJones' lateral approach in the rest. The capsular incision

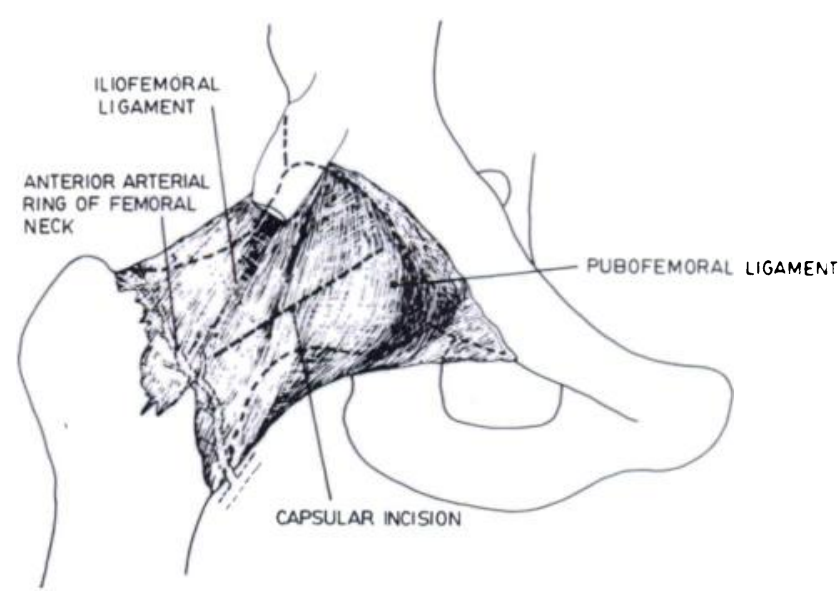

Fig. I

Diagram showing the incision in the anterior capsule, stopping $1 \mathrm{~cm}$ short of the intertrochanteric line, thus sparing the arterial ring. 
is made in the middle of the anterior capsule, stopping $1 \mathrm{~cm}$ short of the intertrochanteric line (Fig. 1). The fibrous tissue between the fragments is scraped out, and the fracture reduced and temporarily fixed with a $\mathrm{K}$-wire penetrating the acetabular floor. A lag screw is then inserted just below the base of the greater trochanter to fix the fracture securely. Meanwhile an assistant removes a $10 \mathrm{~cm}$ length of fibula from the same limb; its sharp interosseous border is nibbled away along its whole length till the medullary cavity is partially exposed, and six drill holes are made at various places in the cortex (Fig. 2). The final length of the fibular graft required for

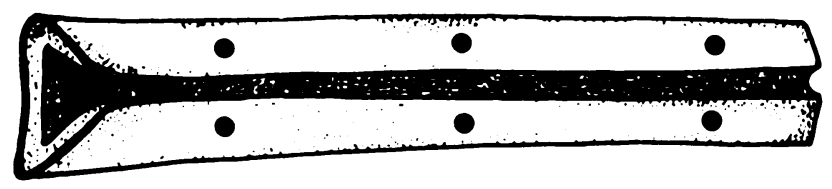

Fig. 2

Drawing of the fibular graft. prepared as described in the text.

fixation is measured by placing it directly over the head, neck and trochanteric region. A Henderson's drill is used to cut a dowel of bone from the lateral cortex of the trochanter and femoral neck just below the screw head, to make a channel for the fibular graft. The graft is then hammered into place, and the acetabular guide-wire removed.

The leg is kept in a Thomas' splint for two weeks, after which the stitches are removed and a single spica cast applied. This cast is removed at the end of six weeks and the patient allowed to walk with crutches, bearing partial weight on the affected limb. Full weight-bearing is generally allowed at the end of three months, but was delayed to six months in four cases where there was significant resorption of the neck with signs of avascular necrosis.

\section{RESULTS}

The results are shown in Tables I and II. There were 14 male and 12 female patients: three were aged 14 to 17 years. eight were aged 31 to 40 and the remaining 15 were 41 to 50 years old. The right hip was affected in 16 patients and the left in 10. Of the 10 fresh femoral neck fractures. six were Garden Type IV and four were Type III. At operation. posterior cortical comminution and a sharp beak on the head fragment were seen in seven of the 10) fresh fractures.

Non-union. All the fractures united except one (Figs 3 to 11). The failure was a technical one--incorrect placement of the cancellous screw (Figs 12 and 13).

Avascular necrosis. There was not a single case of avascular necrosis developing after the operation. In all four patients with radiological signs of avascular necrosis hefore operation. the condition of the femoral head improved after it.
Complications. No serious complications were encountered. Superficial wound infection occurring in two patients responded to appropriate antibiotics. Nonunion occurred in one case where the threads of the cancellous screw did not cross the fracture site; there was no impaction at the fracture site and the gap increased with the passage of time. This patient was lost to follow-up. Three fractures united with mild to moderate coxa vara: all had presented very late after the injury and had gross resorption of the neck. Two of these were children and coxa vara probably developed as a result of injury to the growth plate.

\section{DISCUSSION}

Fifty-five years ago the Smith-Petersen nail was received as the panacea for femoral neck fractures and a welcome departure from Whitman's closed method of treatment (Smith-Petersen, Cave and Vangorder 1931). The procedure was, however, not very successful in Garden Types III and IV fractures, and the total failure rate including non-union and subsequent avascular necrosis was $70.9 \%$ in displaced fractures (Frangakis 1966). The rate of non-union ranged from $11 \%$ to $22 \%$ in various large series (Boyd and George 1947; Boyd and Salvatore

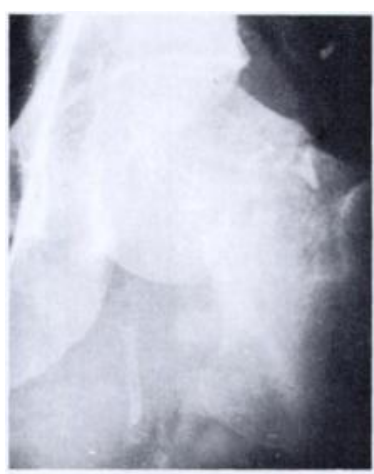

Fig. 3

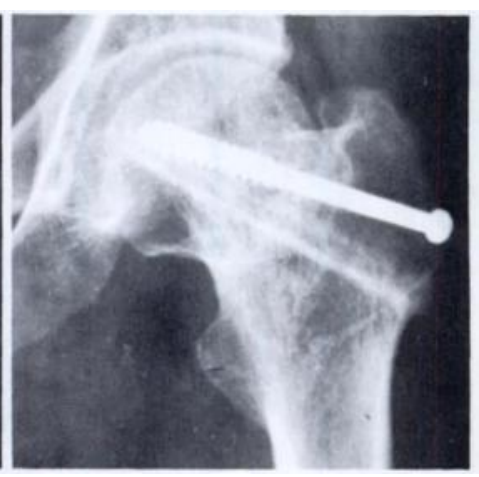

Fig. 4
Case 3. Figure 3-Two-week-old comminuted intracapsular fracture of the neck of the femur. Figure $4-$ Six months after operation there is solid bony union. continuity of the principal compressive trabeculae and partial incorporation of the fibular graft.

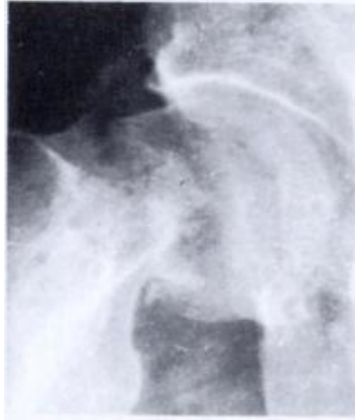

Fig. 5

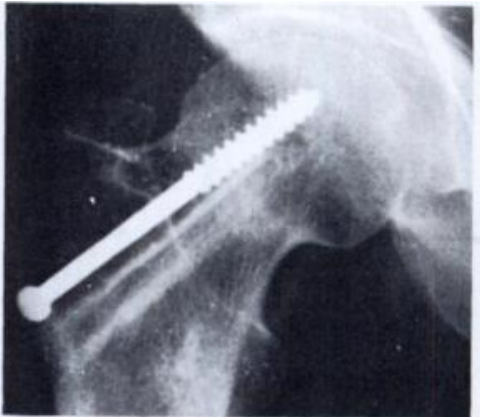

Fig. 6
Case 10. Figure 5 - One-week-old intracapsular fracture. Figure 6

One year after operation there is complete reconstitution of the neck. The patient had a very good range of movement including the ability to squat. 
Table I. Results of osteosynthesis in 10 fresh cases

\begin{tabular}{|c|c|c|c|c|c|c|c|c|}
\hline Case & $\begin{array}{l}\text { Age } \\
\text { (years) }\end{array}$ & Sex & $\begin{array}{l}\text { Side } \\
\text { affected }\end{array}$ & $\begin{array}{l}\text { Time between } \\
\text { injury and } \\
\text { operation } \\
\text { (days) }\end{array}$ & $\begin{array}{l}\text { Posterior } \\
\text { cortical } \\
\text { comminution }\end{array}$ & $\begin{array}{l}\text { Surgical } \\
\text { approach }\end{array}$ & Result & $\begin{array}{l}\text { Follow-up } \\
\text { (months) }\end{array}$ \\
\hline 1 & 45 & $\mathbf{M}$ & $\mathrm{R}$ & 3 & ++ & Lateral & Bony union & 26 \\
\hline 2 & 40) & $\mathbf{F}$ & $\mathrm{L}$ & 7 & + & Lateral & Bony union & 28 \\
\hline 3 & 42 & $M$ & $\mathrm{~L}$ & 14 & + & Lateral & Bony union & 24 \\
\hline 4 & 48 & $\mathrm{~F}$ & $\mathrm{R}$ & 20 & - & Lateral & Bony union & 32 \\
\hline 5 & 39 & $M$ & $\mathrm{~L}$ & 18 & - & Lateral & Bony union & 40 \\
\hline 6 & 23 & M & $\mathrm{R}$ & 2 & ++ & Lateral & Non-union & - \\
\hline 7 & 47 & $\mathrm{~F}$ & $\mathrm{R}$ & 6 & ++ & Lateral & Bony union & 24 \\
\hline 8 & 32 & $\mathrm{~F}$ & $\mathrm{R}$ & 4 & - & Lateral & Bony union & 32 \\
\hline 9 & 43 & $\mathrm{~F}$ & $\mathrm{~L}$ & 2 & + & Lateral & Bony union & 36 \\
\hline 10 & 50 & $M$ & $\mathbf{R}$ & 7 & + & Lateral & Bony union & 29 \\
\hline
\end{tabular}

No patient had avascular necrosis before or after operation

Table II. Results of osteosynthesis in 16 old cases

\begin{tabular}{|c|c|c|c|c|c|c|c|c|c|c|}
\hline \multirow[b]{2}{*}{ Case } & \multirow[b]{2}{*}{$\begin{array}{l}\text { Age } \\
\text { (years) }\end{array}$} & \multirow[b]{2}{*}{ Sex } & \multirow[b]{2}{*}{$\begin{array}{l}\text { Side } \\
\text { affected }\end{array}$} & \multirow{2}{*}{$\begin{array}{l}\text { Time between } \\
\text { injury and } \\
\text { operation } \\
\text { (reeks) }\end{array}$} & \multicolumn{2}{|c|}{ Pre-operative } & \multicolumn{4}{|c|}{ Postoperative } \\
\hline & & & & & Resorption & AVN & $\begin{array}{l}\text { Surgical } \\
\text { approach }\end{array}$ & $\begin{array}{l}\text { Bony } \\
\text { union }\end{array}$ & AVN & $\begin{array}{l}\text { Follow-up } \\
\text { (months) }\end{array}$ \\
\hline 11 & 14 & $\mathbf{M}$ & $\mathrm{R}$ & 6 & - & - & Lateral & + & - & 24 \\
\hline 12 & 42 & $\mathrm{~F}$ & $\mathbf{R}$ & 24 & + & + & Lateral & + & Improved & 26 \\
\hline 13 & 43 & $M$ & $\mathrm{~L}$ & 15 & - & - & Posterior & + & - & 26 \\
\hline 14 & 32 & $\mathrm{~F}$ & $\mathbf{R}$ & 10 & - & - & Lateral & + & - & 30 \\
\hline 15 & 46 & M & $\mathrm{R}$ & 4 & - & - & Lateral & + & - & 32 \\
\hline 16 & 36 & $\mathrm{~F}$ & $\mathrm{~L}$ & 6 & - & - & Posterior & + & - & 24 \\
\hline 17 & 45 & $\mathrm{~F}$ & $\mathrm{~L}$ & 8 & - & - & Lateral & + & - & 28 \\
\hline 18 & 17 & M & $\mathrm{L}$ & 16 & + & + & Lateral & + & Improved & 24 \\
\hline 19 & 37 & $\mathrm{~F}$ & $\mathrm{R}$ & 6 & - & - & Lateral & + & - & 32 \\
\hline 20 & 15 & M & $\mathbf{R}$ & 62 & + & - & Posterior & + & Improved & 34 \\
\hline 21 & 49 & $\mathrm{~F}$ & $\mathbf{R}$ & 10 & - & + & Lateral & + & - & 31 \\
\hline 22 & 46 & $\mathbf{M}$ & $\mathbf{R}$ & 11 & - & - & Lateral & + & - & 37 \\
\hline 23 & 40 & $\mathbf{M}$ & $\mathrm{L}$ & 28 & + & + & Lateral & + & Improved & 33 \\
\hline 24 & 43 & $\mathbf{M}$ & $\mathrm{L}$ & 22 & + & - & Lateral & + & - & 29 \\
\hline 25 & 50 & $\mathbf{M}$ & $\mathbf{R}$ & 4 & - & - & Lateral & + & - & 28 \\
\hline 26 & 50 & $\mathrm{~F}$ & $\mathbf{R}$ & 6 & - & - & Lateral & + & - & 27 \\
\hline
\end{tabular}

AVN, Avascular necrosis 


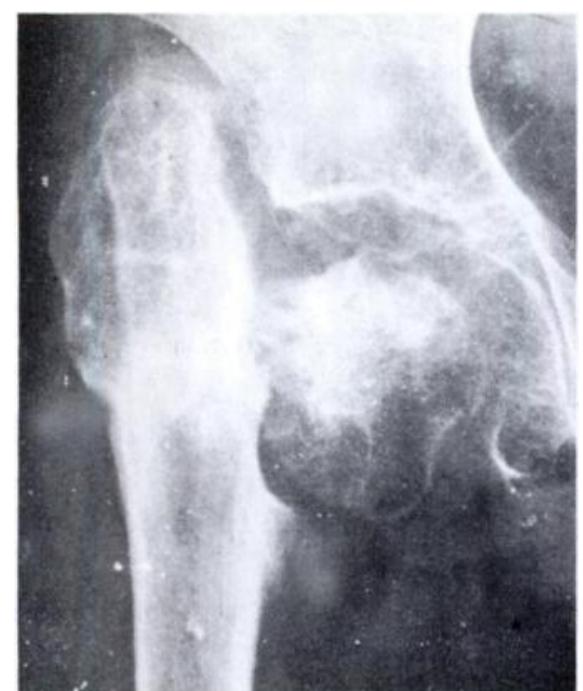

Fig. 7

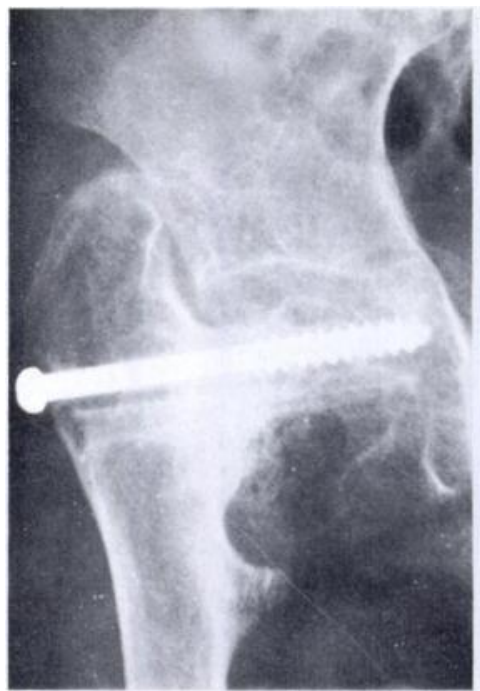

Fig. 8

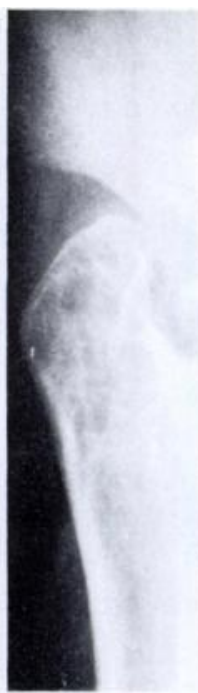

Fig. 9

(ase 20. Figure 7 Sixty-two-week-old intracapsular fracture in a 15-year-old boy, treated elsewhere by an incompletely displaced McMurray s osteotomy. There was resorption of the neck and evidence of avascular necrosis. Figure 8 After osteosynthesis there is almost complete incorporation of the fibular graft with reconstitution at the fracture site. Figure 9 - Thirty-four months after operation the femoral head does not look avascular.

1964). In a long-term investigation of 1503 subcapital fractures, the Smith-Petersen nail was found to be the least effective form of fixation in displaced fractures as compared to the sliding nail, crossed-screw fixation and

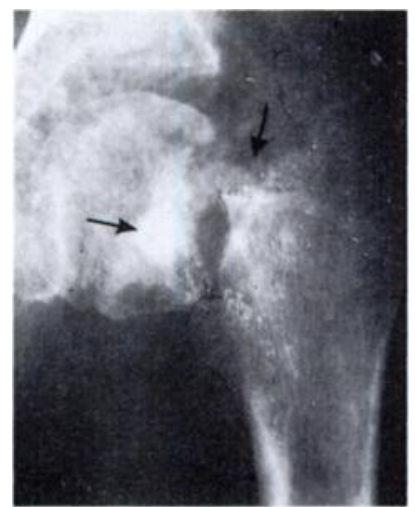

Fig. 10

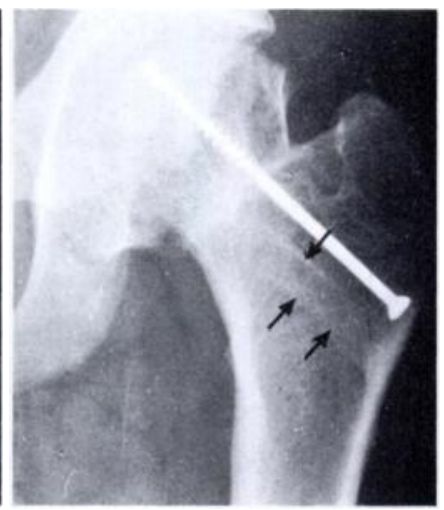

Fig. 11 (ase 18. Figure 10 Four-month-old fracture with avascular necrosis and resorption of the neck. Figure 11 -After 18 months there is complete reconstitution with no obvious avascular necrosis. This patient had full hip flexion so that he was able to squat.

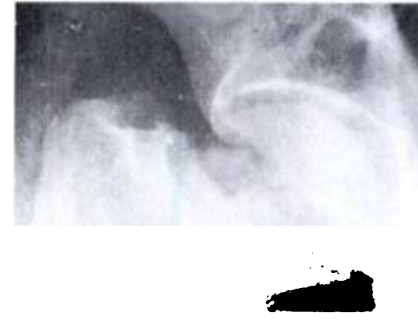

Fig. 12

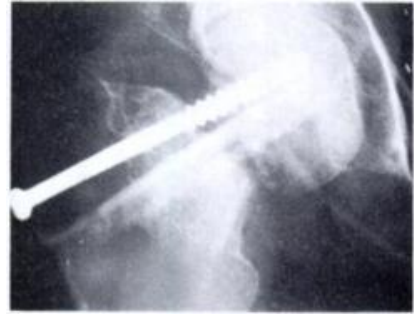

Fig. 13
Case 16. Figure 12 Fractured neck of femur. Figure 13 This was treated by a fibular graft and screw. but the threads of the lag screw did not cross the fracture site. resulting in non-union and distraction at the fracture. triangular fixation (Barnes et al. 1976). The techniques of internal fixation have been modified repeatedly because none was perfect. The newer appliances have a lower rate of non-union than Smith-Petersen nailing: $4.7 \%$ with Deyerle pins and $4 \%$ with Pugh's sliding nail-plate (Metz et al. 1970; Fielding. Wilson and Ratzan 1974). Richard's sliding nail has shown promise; it securely impacts the fragments to each other thus helping early weightbearing. but non-union is still a problem. Parkes reported an $18 \%$ incidence of non-union with Richard's screw (cited by Arnold, Lyden and Minkoff 1974).

In patients below the age of 50 we treated all femoral neck fractures with open reduction and fibular grafting. The mechanical fixation afforded by the various previous devices depends upon the physical pressure exerted between the nail and the bone into which it was driven. Normal vascular bone reacts to this physical pressure by absorption of the bone at the metal interface, especially if the implant is ionisable and not completely inert. This produces a halo of loosening which is supposedly the cause of movement at the fracture site, leading to non-union in a sizeable number of cases (Patrick 1949). By contrast, a fibular graft, at the end of three to four weeks, starts providing biological fixation by beginning to fuse with the parent bone, so that implant loosening does not occur. The procedure was successful in nine of the 10 fresh cases in the present series, and the technical failure in the tenth could have been avoided. Bony union was achieved in these nine cases, with no evidence of avascular necrosis.

Our results were better than similar studies conducted in the past. Inclan (1946) and Patrick (1949) published their results of Smith-Petersen nailing and fibular grafting, reporting a $10 \%$ to $15 \%$ of non-union and avascular necrosis. We attribute our better results to 
atraumatic tissue technique and the use of the lateral approach predominantly, thus sparing the posterior retinacular vessels. The special preparation of the fibular graft also helps in its early incorporation. A cancellous screw provides reasonably good fixation and occupies less space than a nail in the femoral neck. Greater encroachment on this limited space by combining a Smith-Petersen nail with a fibular graft seems to depress the regenerating potential of the head, thus increasing the chances of avascular necrosis. The capsular incision in our cases was made anteriorly between the two limbs of the ligament of Bigelow, starting from the acetabular margin and stopping short at least $1 \mathrm{~cm}$ from the intertrochanteric line. This is thought to be the least vascular area and avoids the major arterial circle around the base of the neck.

Anatomical reduction, impaction of the fragments and rigid fixation are the main factors necessary to achieve the best results in displaced fractures of the femoral neck. All these criteria are eminently fulfilled by open reduction. lag-screw fixation and rigid biological fixation.

The treatment of old femoral neck fractures is a much bigger challenge than that of fresh fractures. Closed reduction and internal fixation is not possible in most displaced fractures after three weeks. A few weeks later the neck begins to resorb and still later the radiological signs of avascular necrosis may appear; the chances of union are then bleak. Most orthopaedic surgeons have in the past treated such fractures with a McMurray`s osteotomy, which often leaves a short limb and a mechanically unsound hip. More recently various muscle-pedicle bone grafting procedures have been tried (Judet 1962; Meyer. Harvey and Moore 1973; Baksi 1983). They seem to hasten union even in the presence of an avascular head. Meyer et al. used quadratus femoris and sartorius muscle-pedicle grafts or a free fibular graft in 136 patients; they had $11 \%$ non-union and $3 \%$ avascular necrosis. Baksi (1983) reported excellent to fair results in treating non-union of the femoral neck plus avascular necrosis of the head with his quadratus femoral or gluteus medius muscle-pedicle bone graft. We achieved union in all 16 old fractures and radiological improvement in four cases of avascular necrosis.
Cortical bone grafting is a recognised method of treating avascular necrosis of the head (Bonfiglio and Voke 1968) and the presence of a fibular strut prevented the collapse of subchondral bone until revascularisation was complete.

\section{REFERENCES}

Arnold WD, Lyden JP, Minkoff J. Treatment of intracapsular fractures of the femoral neck: with special reference to percutaneous Knowles pinning. J Bone Joint Surg $[A m]$ 1974:56 A:254 62 .

Baksi DP. Treatment of post-traumatic avascular necrosis of the femoral head by multiple drilling and muscle-pedicle bone grafting: a preliminary report. J Bone Joint Surg $[B r]$ 1983:65-B: $268-73$.

Barnes R, Brown JT, Garden RS, Nicoll EA. Subcapital fractures of the femur: a prospective review. J Bone Joint Surg $[B r]$ 1976:58 B: 224.

Bonfiglio M, Voke EM. Aseptic necrosis of the femoral head and nonunion of the femoral neck. J Bone Joint Surg $[\mathrm{Am}]$ 1968:50 A 4866 .

Boyd HB, George IL. Complications of fractures of the neck of the femur. J Bone Joint Surg 1947;29:13 8.

Boyd HB, Salvatore JE. Acute fracture of the femoral neck: internal fixation or prosthesis? J Bone Joint Surg [Am] 1964:46 A: 10668.

Cartlidge IJ. Primary total hip replacement for displaced subcapital femoral fractures. Injur 1 1981:13:249 53 .

Coats RL, Armour P. Treatment of subcapital femoral fractures by primary total hip replacement. Injury 1979:11:132 5 .

D'Arcy J, Devas M. Treatment of fractures of the femoral neck by replacement with a Thompson prosthesis. J Bone Joint Surg [Br] 1976: 58 B: 27990

Devas M, ed. Geriatric orthopaedics. London: Academic Press, 1977.

Fielding JW, Wilson SA, Ratzan S. A continuing end-result study of displaced intracapsular fractures of the neck of the femur treated with the Pugh nail. J Bone Joint Surg $[\mathrm{Am}]$ 1974:56 A: 1464-72.

Frangakis EK. Intracapsular fractures of the neck of the femur: factors influencing non-union and ischaemic necrosis. $J$ Bone Joint Surg $[B r]$ 1966:48 B: 1730 .

Inclan A. Late complications in fracture of the neck of the femur treated by nailing. bone grafting or both. J Int Coll Surg 1946:9: 3650 .

Judet $\mathbf{R}$. Traitement des fractures du col du femur par greffe pédiculee. Acta Orthop Scand 1962:32:421 7.

Metz CW Jr, Sellers TD, Feagin JA, et al. The displaced intracapsular fracture of the neck of the femur: experience with Deyerle method of fixation in sixty-three cases. J Bone Joint Surg [Am] 1970;52 A: 11327.

Meyer MH, Harvey JP Jr, Moore TM. Treatment of displaced subcapital and transcervical fractures of the femoral neck by musclepedicle-bone graft and internal fixation: a preliminary report on one hundred and fifty cases. J Bone Joint Surg $[\mathrm{Am}]$ 1973:55-A: 25774.

Patrick J. Intracapsular fractures of the femur treated with a combined Smith-Petersen nail and fibular graft. I Bone Joint Surg $[\mathrm{Am}]$ 1949: 31 A:67 80.

Smith-Petersen MN, Cave EF, Vangorder GW. Intracapsular fractures of the neck of the femur: treatment by internal fixation. Arch Surg $1931: 23: 71559$. 